Jpn. J. Pharm. Health Care Sci.

37(2) $97-103$ (2011)

\title{
Survey of Attitude toward Work among Pharmacists Working in Large Chain Community Pharmacies in Japan
}

\author{
Keiichi Nakagomi ${ }^{* 1}$, Toshihiko Kameya ${ }^{2}$, Katsuhiko Fukai ${ }^{3}$, \\ Nahoko Yamada ${ }^{4}$ and Nobuyuki Kanno ${ }^{5}$ \\ Faculty of Pharmacy, Musashino University ${ }^{1}$, Human Resource Division, Kraft Inc. ${ }^{2}$, \\ Pharmacy Division, Nihon Chozai Inc. ${ }^{3}$, Human Resource Division, Pfercos Inc. ${ }^{4}$, \\ Pharmaceutical Regulatory Affairs, Medical Pharmacy Inc. ${ }^{5}$ \\ Received June 28, 2010 \\ A ccepted November 17, 2010
}

In Japan, many new pharmacy graduates currently look for positions in large chain community pharmacies. We conducted a cross sectional study to obtain information that could be used in career design for pharmacy students by investigating the attitude of pharmacists working in such pharmacies toward their work, especially with regard to job satisfaction, and their future work plans, through a self-administered survey. We had the headquarters of 4 pharmacy chains distribute the survey to 2,071 pharmacists working in their pharmacies.

The proportion of usable data was $76.5 \%$. More than $60 \%$ of the surveyed pharmacists were working as community pharmacists in order to put their license to good use or because they wished to work in the health care field. Though $90 \%$ of the pharmacists were satisfied with their jobs, only $7.6 \%$ of them could see themselves remaining in their current jobs until retirement. Therefore, job satisfaction among pharmacists was considerably higher than it was for college graduates, expert workers and technicians in general. It was felt that pharmacists' future work plans was affected by age, job satisfaction, years employed and gender.

The results of our survey suggest that pharmacists working in large chain community pharmacies are dedicated profes sionals who are highly motivated, have a tendency to change jobs, and mostly female. It seems that generally speaking, pharmacists are more interested in their field of expertise than their workplace as compared with workers in other profes sions.

Key words — pharmacist survey, community pharmacist, chain pharmacy, work attitude, job satisfaction, future work plan

\section{Introduction}

In general, as employee job satisfaction increases, cus tomer or patient satisfaction also rises ${ }^{1,2)}$. Community pharmacists were less satisfied with their situation, and their job satisfaction was significantly different depending on gender and years experience ${ }^{3)}$. The factors impacting job satisfaction of community pharmacists were 'Management policy', ' Work environment' and' Organizational administration', but not Individual motivation' *a. Hospital pharmacists considered that their duties were worthwhile, although they were dissatisfied with their status in their institution ${ }^{4}$. A common factor influencing job satisfaction was" the upbeat atmosphere", although various factors were found among hospital employees ${ }^{2}$. There are several reports concerning work attitude of Japanese pharmacists as the above studies, while these studies do not focus on comparison of work attitude between pharmacists and ordinary workers.
In studies conducted outside Japan, pharmacists were satisfied with their job ${ }^{5}$, and job/career satisfaction and turnover intention were important quality-of-worklife issues from the pharmacists' perspective ${ }^{6}$. The average annual turnover rate and the average term employment were dis cussed $^{7}$. Future work plans were found to be influenced by a variety of individual, organizational, and cultural/climatic factors $^{8}$. There are not many discussion of job satisfaction, turnover and future work plans in chain community pharma cists in Japan.

Today in Japan, many new pharmacy graduates seek work in chain community pharmacies, which hardly existed in the Japanese labor market in the early 1990s. The object of this study is to investigate the work attitude, especially, job satis faction and future work plans of community pharmacists in the chain pharmacies, which could help student career de sign. 


\section{Methods}

After each company agreed to participate in this study, the questionnaires were designed and revised so that respondents could complete them in as short a time as possible. Predetermined answers were categorized in order to examine issues related to work attitude. A self-administered survey of cross sectional studies was conducted. Basic demographic items consisted of employment status (regular ${ }^{*} \mathrm{~b} / \mathrm{non}$ regular ${ }^{*}$ ), gender, marital status, age (5categories), and years employed in the current workplace (5categories). Three other questions were asked: the number of pharma cists in the current workplace, the number of workplaces changed, and the number of pharmacies served since graduation. With regard to the work attitude of the pharmacists, seven questions were asked: the main reason for being a community pharmacist, reasons for choosing the current workplace (ranked to top three), the most important workrelated concerns, job satisfaction, reasons for any dissatisfaction with the current workplace, future work plans and, for those who had changed to the current workplace, reasons for leaving the previous workplace (ranked to top three).

Pharmacists were informed by their supervisor that participation in this unsigned survey was voluntary, and that the data would be used only for research, and sealed answer sheets were mailed directly to the investigator. The survey was conducted between December 2007 and January 2008. The surveyed data were tested with chi-square tests, Wilcoxon rank-sum test and Kruskal-Wallis test depending on data by using SPSS $16.0 \mathrm{~J}$ for Windows (SPSS Japan Inc., an IBM company). Quantification theory 1 for job satisfaction and Quantification theory 2 for future work plans (Esumi Co. Ltd.) were used, respectively. A p value less than 0.05 was defined as statistically significant $a$ priori.

\section{Results}

The rate of usable data was $76.5 \%$ : the number of usable data from a total of 2,071 pharmacists was 1,585 , which completed the basic demographic data. The effective data for each question, where those with missing answers were excluded, from the usable 1,585 data were analyzed.

Here are the characteristics of our respondents (Table 1) : approximately female $70 \%$, single $60 \%$, regular employment $80 \%, 22-29$ years $50 \%$ and less than 3years employed $50 \%$. Comprehensive results were shown in the Table 2. Main reason for being a community pharmacist: more than $60 \%$ of the respondents were interested in putting their license into practice, identified as practical utilization of pharmacist license' (42.8\%) and 'desire to work in healthcare field' $(21.7 \%)$. The highest ranked reason for choosing the current workplace was well-known large com- pany' (36.5\%), followed by' employment terms and conditions' $(15.3 \%)$.

Running from the most important work, the concerns were! work content' (33.2\%), interpersonal relationship' (25.6\%), and 'work and family life balance' (20.3\%). Respondents were asked to place their personal level of job satisfaction within the following parameters: 80-100 pts., 70 -79 pts., $60-69$ pts., $50-59$ pts. and $<50$ pts. with a total one hundred points (pts.). Approximately $90 \%$ of the respondents reported a rate of satisfaction above 60 points. ' Employment terms and conditions' (29.0\%) was ranked as the largest area of dissatisfaction followed by' salary' (27.4 $\%)$. Regarding the future work plans the respondents choos ing stay until retirement' were only $7.6 \%$. Main reasons for turnover: approximately half of the respondents had changed jobs. The two main reasons for leaving their previous work place were! family issues' (27.5\%), and ' employment terms and conditions' (20.3\%).

Differences among demographic characteristics were found (Table 3). There were significant differences between single and married in all questionnaire items. Job satisfaction data showed significant differences in employment status, marital status, years employed and the number of pharma cies joined after graduation in main categories. Significant differences in job satisfaction of regular employment data were exhibited between males and females, single males and females, and married males and females. Future work plan data showed significant differences in all basic demographic characteristics such as employment status, gender, marital status, age and years employed, and among all groups of regular employment.

The relationships between job satisfaction and all ques tionnaire items were analyzed by Quantification theory 1. However, the coefficient of determination in this analysis satisfaction came to 0.199, clearly an unreliable analysis re sult (usually more than 0.5 is preferable). Therefore, it was not recognized this specific item affected job satisfaction. Relationships between future work plans and all questionnaire items were analyzed by Quantification theory 2. The correlation ratio between' stay until retirement' and 'stay for less than 5 years' was $0.471(p=0.000)$, a moderate correlation. Possible items affecting future work plans were gender $(p=0.000)$, age $(p=0.000)$, job satisfaction $(p=$ $0.000)$, years employed $(p=0.001)$ and employment status $(p=0.040)$. A category score $(+)$ indicates the influence of ' stay until retirement' and $(-)^{4}$ stay for less than 5 years' (Fig. 1). The categories of age (more than 40 years), job satisfaction (80-100 points), years employed (more than 10 years) and gender (male) in order of strength also affected future work plans. On the other hand, the categories of job satisfaction (less than 50 points) and age (26-29years) may have influenced' stay for less than 5 years'. This model

${ }^{*} \mathrm{~b}$ directly employed as full-time pharmacists

${ }^{*} \mathrm{c}$ any pharmacists who were not regular 
Table 1 . Demographics of Respondents

\begin{tabular}{|c|c|c|}
\hline Characteristics & & Respondents (\%) \\
\hline Employment status & $\begin{array}{l}\text { Regular } \\
\text { Non-regular }\end{array}$ & $\begin{array}{l}1,270(80.1 \%) \\
315(19.9 \%)\end{array}$ \\
\hline Gender & $\begin{array}{l}\text { Male } \\
\text { Female }\end{array}$ & $\begin{array}{l}499(31.5 \%) \\
1,086(68.5 \%)\end{array}$ \\
\hline Marital status & $\begin{array}{l}\text { Single } \\
\text { Married }\end{array}$ & $\begin{array}{l}955(60.3 \%) \\
630(39.7 \%)\end{array}$ \\
\hline Age & $\begin{array}{l}22-25 \\
26-29 \\
30-34 \\
35-39 \\
>40\end{array}$ & $\begin{array}{l}376(23.7 \%) \\
446(28.2 \%) \\
328(20.7 \%) \\
162(10.2 \%) \\
273(17.2 \%)\end{array}$ \\
\hline $\begin{array}{l}\text { Years employed in the current } \\
\text { workplace }\end{array}$ & $\begin{array}{l}<1 \\
2-3 \\
4-5 \\
6-9 \\
>10\end{array}$ & $\begin{array}{l}364(23.0 \%) \\
460(29.0 \%) \\
264(16.7 \%) \\
354(22.3 \%) \\
143(9.0 \%)\end{array}$ \\
\hline $\begin{array}{l}\text { The number of pharmacists in } \\
\text { the current workplace }\end{array}$ & $\begin{array}{l}<4 \\
5-9 \\
10-14 \\
>15\end{array}$ & $\begin{array}{l}735(46.4 \%) \\
603(38.0 \%) \\
202(12.7 \%) \\
45(2.8 \%)\end{array}$ \\
\hline $\begin{array}{l}\text { The number of workplace changed } \\
\text { since graduation }\end{array}$ & $\begin{array}{l}1 \\
2 \\
3 \\
4 \\
>5\end{array}$ & $\begin{array}{l}808(51.0 \%) \\
309(19.5 \%) \\
225(14.2 \%) \\
129(8.1 \%) \\
114(7.2 \%)\end{array}$ \\
\hline $\begin{array}{l}\text { The number of pharmacies served } \\
\text { since graduation }\end{array}$ & $\begin{array}{l}1 \\
2 \\
3 \\
4 \\
>5\end{array}$ & $\begin{array}{l}1,103(69.6 \%) \\
275(17.4 \%) \\
136(8.6 \%) \\
41(2.6 \%) \\
30(1.9 \%)\end{array}$ \\
\hline
\end{tabular}

confirmed $98.4 \%$ of predictive value for stay for less than 5 years' and $52.9 \%$ for stay until retirement' based on calculated and actual data.

\section{Discussion}

It is worth noting that the rate of regular employees (80.1 $\%$ ) in our study is higher than that $(57.7 \%)$ in the retail sale sector ${ }^{*}$. Female pharmacists amounted to $68.4 \%$ in our study and $73.9 \%$ in MHLW survey (community pharma cists, excluding owners) ${ }^{*} \mathrm{e}$. Note also that the age of more than half of our samples was less than 29 years, younger than the average age of community pharmacists (42.1 years) ${ }^{*}$. . These results support that : clearly, female pharma cists constitute an important work force in community phar- macies and chain pharmacies are able to recruit younger pharmacists. Pharmacists, it seems, are able to obtain regular employment positions with ease. However, when pharmacy graduates increase by $40-50 \%$ from 2012 , the situation may not be so clear cut.

In our study the main reason given for being a community pharmacist was the practical utilization of pharmacist license' and' desire to work in healthcare', indicating a strong career commitment among community pharmacists.

According to foreign studies, among the surveyed pharmacists, $67.2 \%$ were satisfied with their job ${ }^{5}$, compared to $68 \%$ in another similar study ${ }^{9}$. Ninety-six percent of the pharmacists in our study were satisfied if we followed the standard of 50-59 pts. as' neither' in the MHLW study ${ }^{*}$ (Table 4). In comparison, pharmacists were much more sat-

${ }^{*} d$ Ministry of Health, Labour and Welfare, Monthly Labour Survey (January 2008), www.mhlw.go.jp/toukei/itiran/roudou/monthly/ 20/2001 r/mk 2001 r.html (accessed 2008 Nov 6)

${ }^{*}$ e Ministry of Health, Labour and Welfare, Survey of Physicians, Dentists and Pharmacists 2006, www.mhlw.go.jp/toukei/saikin/hw/ ishi /06/kekka 3-1.html (accessed 2008 Oct 30) 
Table 2 . Summary of Work A ttitude

\begin{tabular}{|c|c|c|c|}
\hline Item & $\%$ & Item & $\%$ \\
\hline Reasons for being community pharmacists $(1,579)$ & & Reasons for dissatisfaction $(1,529)$ & \\
\hline 1.Practical utilization of pharmacist license & 42.8 & 1. Salary & 27.5 \\
\hline 2. Salary & 3.3 & 2. Employment terms and conditions & 29.0 \\
\hline 3. Opportunity for personal development & 15.1 & 3. Lack of personal development & 2.7 \\
\hline 4. Desire to work in health care field & 21.7 & 4. Evaluation toward myself & 1.4 \\
\hline 5. Continuous lcarning & 8.7 & 5. Employecs training systcm & 1.6 \\
\hline 6. Easy work Years employed & 0.9 & 6. Interpersonal relationship & 3.6 \\
\hline \multirow[t]{2}{*}{ 7. Others } & 7.6 & 7. Workplace circumstances & 6.2 \\
\hline & & 8. Hard work & 13.4 \\
\hline Reasons for choosing current workplace* $(1,580)$ & & 9. Work content issues & 6.3 \\
\hline 1. Well-known large company & 36.5 & 10. Others & 8.3 \\
\hline 2. Policy and mission & 7.8 & & \\
\hline 3. Listed company & 1.6 & Future work plans $(1,568)$ & \\
\hline 4. Salary & 2.0 & 1. Stay until retirement & 7.6 \\
\hline 5. Employment terms and conditions & 15.3 & 2. Stay for long term (more than 5 years) & 30.1 \\
\hline 6. Opportunity for personal development & 7.0 & 3. Stay for less than 5 years & 26.0 \\
\hline 7. Employees training system & 11.5 & 4. Undecided & 36.3 \\
\hline 8.Convenient commute & 10.0 & & \\
\hline 9. Recommendation from senior or friend & 4.2 & Reasons for turnover $*(711)$ & \\
\hline \multirow[t]{2}{*}{ 10. Others } & 4.1 & 1. Salary & 6.9 \\
\hline & & 2. Employment terms and conditions & 20.3 \\
\hline Most important work-related concerns $(1,578)$ & & 3. Lack of personal development & 14.5 \\
\hline 1. Salary & 5.8 & 4. Evaluation toward myself & 0.7 \\
\hline 2. Work content & 33.2 & 5. Employees training system & 1.7 \\
\hline 3. Employment stability & 6.5 & 6. Interpersonal relationship & 7.2 \\
\hline 4. Work schedule & 6.0 & 7. Workplace circumstances & 0.8 \\
\hline 5. Work and family life balance & 20.3 & 8. Work content issues & 7.5 \\
\hline 6. Workplace circumstances & 1.6 & 9. Family issucs & 27.4 \\
\hline 7. Interpersonal relationship & 25.6 & 10. Others & 13.0 \\
\hline 8. Others & 1.0 & * Listed reasons rank first from top three & \\
\hline \multicolumn{4}{|l|}{ Job satisfaction $(1,581)$} \\
\hline 1. $80-100$ points & 17.8 & & \\
\hline 2. $70-79$ points & 42.8 & & \\
\hline 3. $60-69$ points & 27.3 & & \\
\hline 4. $50-59$ points & 8.6 & & \\
\hline 5. $<50$ points & 3.5 & & \\
\hline
\end{tabular}

isfied with their job than college graduate workers, expert workers, technologists ${ }^{* f}$ and that of the above foreign studies. However, a few pharmacists believed that they would continue working at their current workplace until retirement in our study. Pharmacists tend to commit to their profession rather than from the workplace itself. We could not explain factors of job satisfaction from our study, whereas it was discussed that main factor of that was fair evaluation' in physicians,' cooperative environment' in nurses, and performance evaluation with career development' and innova tive work environment' in pharmacists among hospital professional ${ }^{2}$. Enrolling in continuous educational programs and precept students affect job and career satisfaction ${ }^{10)}$.

' Salary' was the major reason for dissatisfaction regard-

${ }^{*} f$ Ministry of Health, Labour and Welfare, Survey on Workers who Changed Jobs (2006), www.mhlw.go.jp/houdou/2007/08/h 08082.html (accessed 2008 Oct 30) 
Table 3 . A p value of Statistical A nalysis

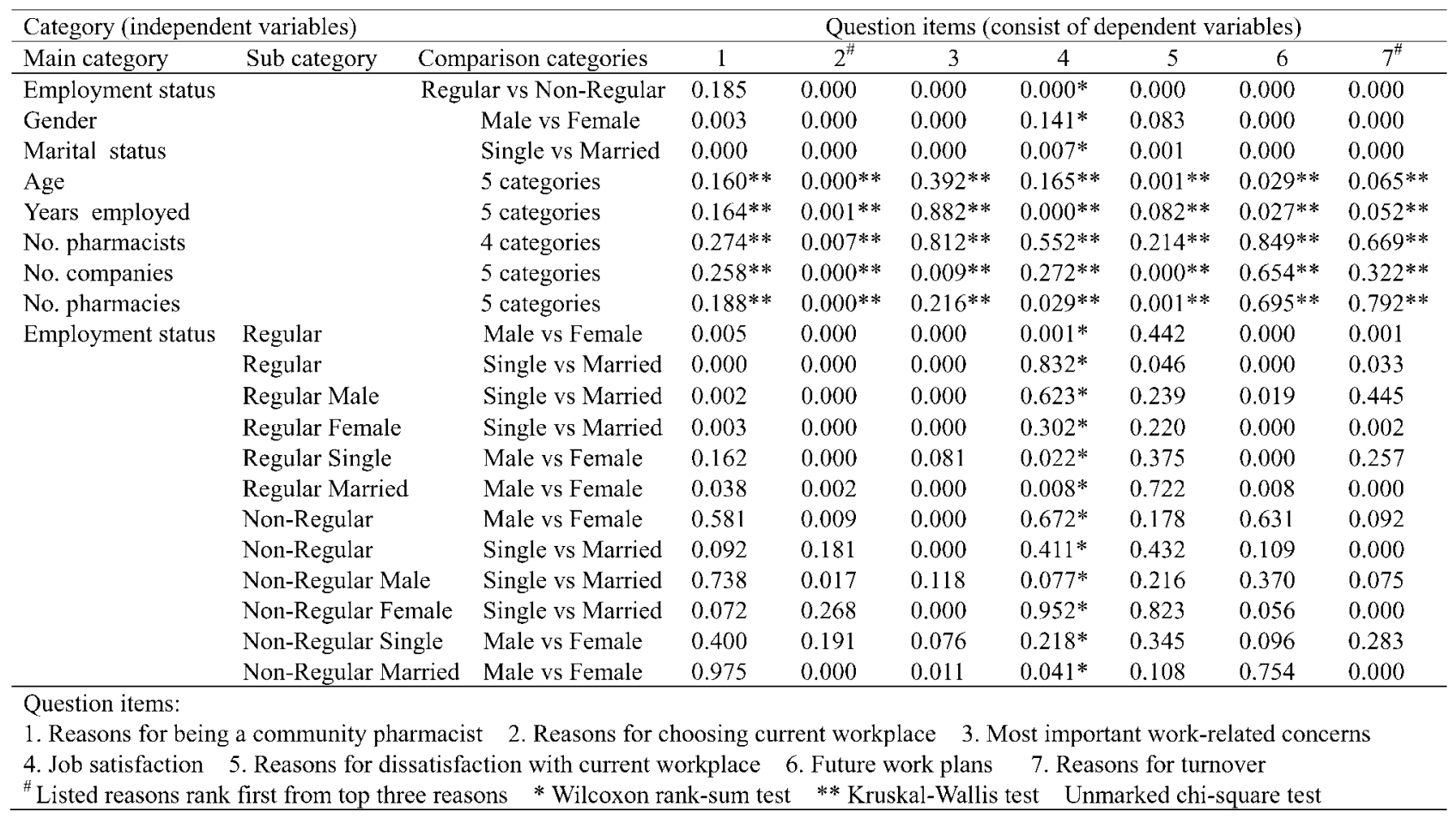

less of occupation or gender ${ }^{*}$, whereas it is interesting that salary (25.3\%) was the major reason for dissatisfaction even though only $5.8 \%$ of the pharmacists in our survey reported that salary was an important work-related concern.

Regarding turnover,' salary' for males,' family issues' for females, and' employment terms and conditions' for both were common reasons given by all workers ${ }^{*}$, including pharmacists in our study. In particularly,' lack of personal development' was a specific reason given by male pharmacists for changing jobs.

Today community pharmacies are undergoing staff and re tention problems, while staff turnover is a persistent issue in the pharmacy sector and pharmacists' labor market ${ }^{7)}$. Pharmacists tend to leave their workplace for the desire to change, because of stress ${ }^{9}$. We indicated that age, job satis faction, years employed and gender may all have influenced future work plans. It is confirmed that these factors are very important for pharmacy managements to allocate human re source in order to operate pharmacies efficiently.

In overseas reports, the annual turnover rate of women $(15 \%)$ is significantly higher than that of men $(9.7 \%)$, and the average term in post among women ( 25.2 months) is significantly less than that among men ( 56.5 months $)^{7}$. Several factors are analyzed to explain turnover. A good salary and good relationships with coworkers are the most common reasons given for staying in a job ${ }^{9}$. Job satisfaction and intention to leave pharmacy were influenced by respondents' strength of motivation as pharmacists ${ }^{11}$. An increase in the mean level of job satisfaction and organizational commit- ment can be said to have decreased the likely incidence of the intention to seek new employment ${ }^{12)}$. Family-friendly flexible work conditions might be more effective in increas ing and keeping a steady workforce than simply raising sala ries $^{13)}$ : Personally rewarding' was the most important factor for pharmacists in 1980's when choosing their first posi$\operatorname{tion}^{14}$, but, on the other hand, the work environment was the most important factor in the view of today's pharmacy students $^{15)}$. Pharmacists' work attitude has been waving and changing. As such, the characteristics of pharmacists be tween the U.S., UK and Japan have many similarities.

\section{Conclusion}

This report provided a descriptive overview of the situation among community pharmacists in large chain pharma cies. Community pharmacists are dedicated to their profes sion, and highly motivated, prone to changing jobs, and mostly female. This study demonstrates that job satisfaction among pharmacists is considerably higher than it is among college graduate workers, expert workers and technologists. It indicated that pharmacists' future work plans may be affected by age, job satisfaction, years employed and gender. We hope that our findings may serve as a fundamental re source for understanding the way of pharmacists feel about the work that they do, and complement other research in this area. 


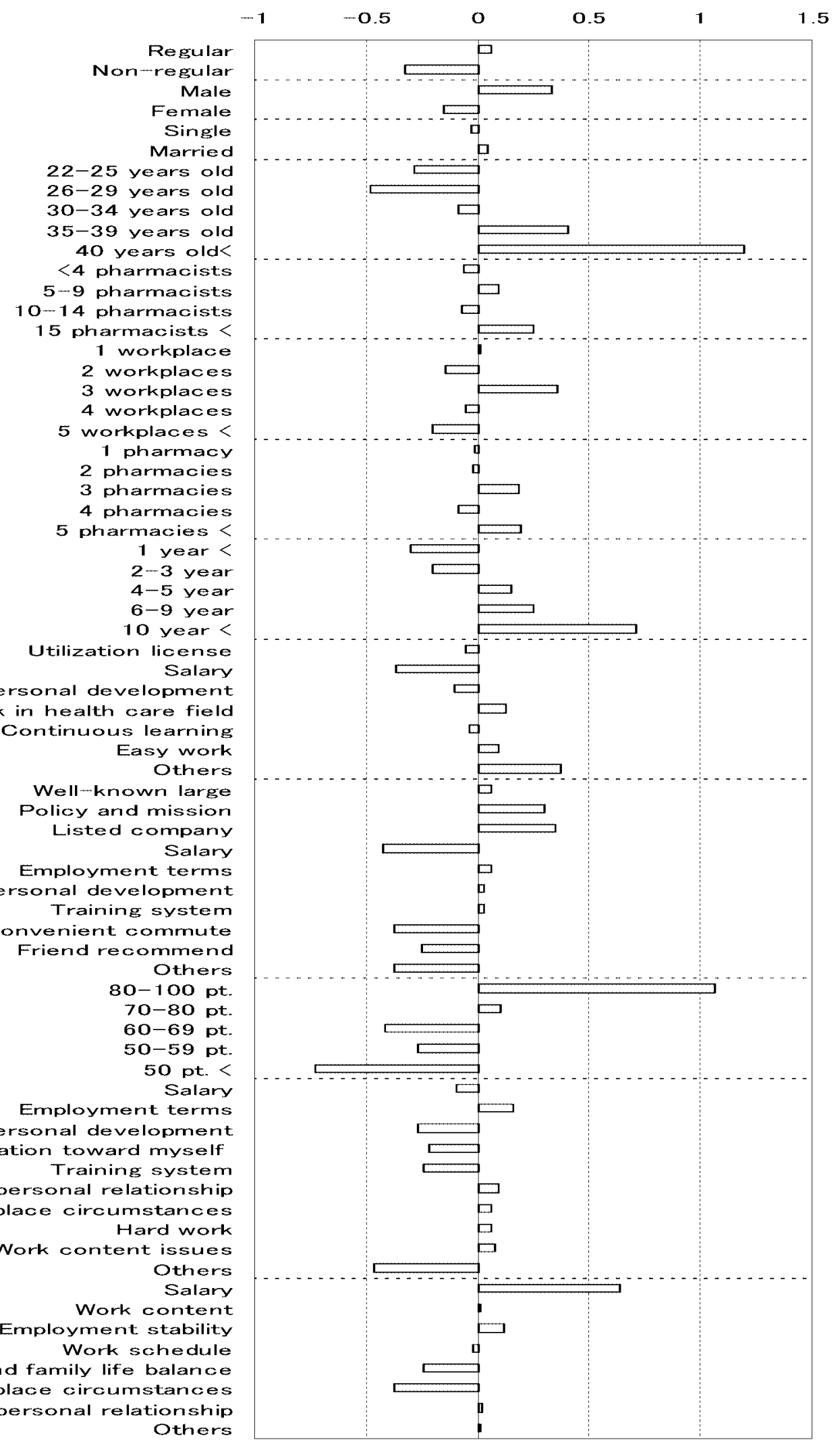

Fig 1. Category Score of Items toward Future Work Plans 
Table 4 . Job Satisfaction

\begin{tabular}{lc||lcc}
\hline \multicolumn{2}{c||}{ Our Study } & \multicolumn{3}{c}{ MHLW Survey* } \\
\cline { 3 - 4 } Degree category & \multirow{2}{*}{ Pharmacists (\%) } & Rating scale & College graduates (\%) & $\begin{array}{l}\text { Expert workers/ } \\
\text { Technologists }(\%)\end{array}$ \\
\hline $80-100$ pts & 15.1 & Satisfaction & 27.3 & 23.8 \\
$70-79$ pts & 42.9 & Less satisfaction & 38.9 & 36.9 \\
$60-69$ pts & 28.9 & Neither & 17.0 & 19.1 \\
$50-59$ pts & 9.1 & Less dissatisfaction & 11.2 & 14.1 \\
$<50$ pts & 4.0 & Dissatisfaction & 5.1 & 5.5 \\
& & NA & 0.5 & 0.6 \\
\hline
\end{tabular}

* Ministry of Health, Labour and Welfare, Survey on Workers who Changed Jobs (2006), www.mhlw.go.jp/houdou/2007/08/h0808-2.html (accessed 2008 Oct 30)

Acknowledgement We gratefully acknowledge the assis tance of all the pharmacists who participated in this survey, at Nihon Chozai Inc., Kraft Inc., Pfercos Inc., and Medical Pharmacy Inc.. A Iso we acknowledge the participating of Mr. Issei NAKAGAWA of the Misumi Co. Ltd. who gave expert advice.

Selected findings were presented at the $129^{\text {th }}$ A nnual Meeting of the Pharmaceutical Society of Japan in Kyoto, Japan in March 2009 and the $19^{\text {th }}$ A nnual Meeting of the Japanese Society of Pharmaceutical Health Care and Science in Nagasaki, Japan in October 2009. There is no funding and conflict of interest in this study.

Limitation Only four chain pharmacies were surveyed, which do not represent whole community pharmacies in Japan. This study is positioned as a pilot study for further researches which focus on job satisfaction, turnover and future work plans.

\section{References}

1) C. Morifuji, Employee satisfaction, Pharma Next, No.60, 57-59 (2008).

2) M. Onda, T. Matsuda, K. Y amakado, Factors influencing pharmacist job satisfaction in hospitals - Observations based on comparison among professionals-, Jpn. J. Soc. Pharm., 25 , 9-18 (2007).

3) K. Okumoto, H. Sanagawa, E. P. A rmstrong, M. Makimura, Jpn. J. Pharm. Health Care Sci., 32 , 146-153 (2006).

4) H. Saitoh, M. Umemura, Report of results regard survey of introducing pharmacists specialist - hospital pharmacist as sociation oncology study, Aichi Prefectural J.Hosp. Pham., 31 , 53-56 (2003).

5) D.A. Mott, W.R. Doucette, C.A. Gaither, C.A. Pedersen, J. C. Schommer, Pharmacists' attitude toward worklife: Re- sults from a national survey of pharmacists, J. Am. Pharm. Assoc., 44 , 326-336 (2004).

6) P.P. McHugh, Pharmacists' attitudes regarding quality of worklife, J. Am. Pharm. Assoc., 39 , 667-676 (1999).

7) D.A. Mott, Pharmacist job turnover, length of service, and reasons for leaving, 1983-1997, Am. J. Health Syst. Pharm., 57 , 975-984 (2000).

8) C.A. Gaither, A. Nadkarni, D.A. Mott, J.C. Schommer, W. R. Doucette, D.H. Kreling, C.A. Pedersen, Should I stay or should I go? The influence of individual and organizational factors on pharmacists' future work plans, J. Am. Pharm. Assoc., 47, 165-173 (2007).

9) V. Maio, N. I. Goldfarb, C. W. Hartmann, Pharmacists' job satisfaction : $V$ ariation by practice setting, $P \& T$., 29,184 190 (2004).

10) M. M. Murawski, N. Payakachat, C. Koh-Knox, Factors affecting job and career satisfaction among community pharmacists: A structural equation modeling approach, J. Am. Pharm. Assoc., 48 , 610-620 (2008).

11) E. Seston, K. Hassell, J. Ferguson, M. Hann, Exploring the relationship between pharmacists' job satisfaction, intention to quit the profession, and actual quitting, Res. Social Adm. Pharm., 5 , 121-132 (2009).

12) C. A. Gaither, Career commitment: a mediator of the effects of job stress on pharmacists' work-related attitudes, J. Am. Pharm. Assoc., 39 , 353-361 (1999).

13) W. Gidman, J. Day, K. Hassell, K. Payne, Delivering health care through community pharmacies: are working conditions deterring female pharmacists' participation?, J. Health Serv. Res. Policy, 14, 141-149 (2009).

14) E. A. Carter, R. Segal, Factors influencing pharmacists' se lection of their first practice setting, Am. J. Hosp. Pharm., 46, 2294-2300 (1989).

15) L. M. Savage, J. W. Beall, T. W. Woolley, Factors that influence the career goals of pharmacy students, Am. J. Pharm. Educ., 73 , 28 (2009). 